\title{
Beyond the lecture: Teaching for professional development
}

\author{
M Rowe, $\mathrm{PhD}$ \\ Department of Physiotherapy, Faculty of Community and Health Sciences, University of the Western Cape, Cape Town, South Africa
}

Corresponding author: $M$ Rowe (mrowe@uwc.ac.za)

Background. Clinical educators are being challenged to graduate students who can adapt to complex situations. Evidence suggests that one must go beyond teaching students what to know and what to do, and help them learn how to be.

Objective. To identify teaching strategies that could be used to help develop students beyond technical proficiency.

Methods. This study used a nominal group technique to gather input from clinical educators, requesting them to identify teaching strategies for developing lifelong learning, emphasising the development of students' knowledge and skills, and taking into account students' emotional responses to the clinical context. Participant responses were transcribed and analysed thematically.

Results. Participants reported that clinical educators should be role-models to students in a process of lifelong learning, including demonstrating the vulnerability of 'not knowing. They also suggested integrating a variety of different teaching methods that aim at achieving the same goal. Finally, participants emphasised the importance of intentionally incorporating personal values into reflective learning activities. By creating space for the shared learning experiences of teachers and students, participants highlighted the possibility of helping students to develop the mindset necessary to adapt to complex health systems.

Conclusion. Clinical educators emphasised the developmental nature of the teaching and learning process, highlighting the importance of an authentic interaction between students and teachers.

Afr J Health Professions Educ 2016;8(2):208-210. DOI:10.7196/AJHPE.2016.v8i2.787

As health systems become more complex and accordingly place a heavier burden on healthcare professionals, it is evident that healthcare education has not kept up with this changing situation. Curricula have been described as 'fragmented, outdated, and static' and continue to produce graduates who have difficulty coping with the complexity of modern health systems. ${ }^{[1]}$ While the science of medicine has changed significantly in the past few decades, the teaching of medicine has not undergone significant change. ${ }^{[1-2]}$ Systemic problems include, e.g. poor alignment between graduate competencies and patient needs, poor teamwork, distracted and over-committed teachers, ossified curricular structures, archaic assessment practices, and a focus on the technical aspects of knowledge and practice without emphasising contextual understanding. ${ }^{[1,3]}$ It has been suggested that healthcare professionals must be more than technically competent. The modern healthcare professional is not necessarily someone who knows all the facts, but is rather able to access knowledge efficiently and when necessary, and is capable of forming conceptual relationships between seemingly unrelated areas. ${ }^{[4]}$

There is evidence to support the use of learning theories to change practice and enhance students' learning; yet, clinical educators continue to use teaching strategies that 'knowingly fail to change behaviour. ${ }^{[2]}$ Teachers who solely adopt a transmission-based approach to teaching may encourage the rote learning of facts and a resultant superficial understanding of the topic. ${ }^{[5]}$ Many teachers still adopt an almost exclusive emphasis on developing knowledge and technical skills as part of competent practice. However, a focus on competence alone is inadequate to produce graduates who are capable of adapting to the changing needs of health systems.

While knowledge and technical skills are essential aspects of clinical education, we must go beyond teaching students what to know and what to do. We must help them to learn how to be by using teaching methods that focus on the process of learning rather than the memorisation of content. ${ }^{[6]}$ We need to create learning spaces where students can be introduced to, and immersed in, the culture of the profession, giving them the feeling of what it is like to be legitimate peripheral participants in a community of practice, ${ }^{[7]}$ i.e. what is learnt should be subordinate to how it is learnt. ${ }^{[8]}$
This study sought to answer the question: What teaching strategies can be used to facilitate a developmental learning process that does not emphasise simply 'having' knowledge and skills? The objective of the study was to identify the teaching strategies that could be used to help students to develop a set of attributes that go beyond technical proficiency.

\section{Methods}

This study used a nominal group technique (NGT) to gather input from a panel of clinical educators who were experts in different knowledge domains. The NGT is used to gather data from domain experts with the intention of reaching consensus, often around poorly defined topics ${ }^{[9]}$ that would include the development of alternative approaches to a curriculum. The NGT was conducted in 2012 in an online workspace in which panellists shared their responses to guided questions. There were three sessions; after each session the researcher aggregated participant responses and presented additional follow-up questions based on the summarised responses, giving participants further opportunities to clarify their statements and make alternative suggestions.

The panel consisted of purposively selected South African and international clinical educators who had experience in the training of healthcare students (Table 1). Panel participants were conveniently selected from the researcher's professional network, and therefore included a greater number of physiotherapists. The purpose of the demographic information was to demonstrate the credibility of the panel as a whole, rather than to describe individual qualifications. The main purpose of the discussion was to ask panel members how they would go about creating an environment where students could engage in learning tasks that helped them to develop attributes beyond technical proficiency.

\section{Data analysis}

Panel members submitted their responses to the questions in an online workspace, which the researcher used to gather and summarise the data. Inductive analysis 
Table 1. Demographic information of panel members

\begin{tabular}{ll}
\hline Demographic information & Panel, $\boldsymbol{n}=\mathbf{2 1}$ \\
\hline Occupation & \\
$\quad$ Professor & 3 \\
Lecturer & 4 \\
$\quad$ Clinician & 3 \\
$\quad$ Other & 11 \\
Profession & \\
$\quad$ Physiotherapist & 8 \\
$\quad$ Physician & 3 \\
$\quad$ Other & 2 \\
Experience, years & \\
$\quad$ Range & \\
$\quad$ Average & $4-25$ \\
Highest degree obtained & 14 \\
$\quad$ BSc & \\
MSc & 4 \\
PhD & 3 \\
$\quad$ MMed & 4 \\
Additional qualifications & 1 \\
Educational & \\
Clinical & 4 \\
Other & 11 \\
${ }^{*}$ Not all participants completed every section of the demographic \\
survey; hence, the totals are inconsistent.
\end{tabular}

was used to determine themes emerging from the data, rather than using predetermined themes. ${ }^{[10]}$ Words and phrases were highlighted as being similar or belonging to the same categories, which were then used to determine the themes. Participant responses were analysed thematically until saturation was reached. ${ }^{[1]}$ These emergent themes were then summarised and re-presented to panel members for clarification and further comment.

Trustworthiness of the analysis was established using a framework for qualitative research that identified the following criteria against which to judge the work: credibility, transferability and dependability. ${ }^{[10]}$ The analysis, emergent themes and subsequent surveys were cross-checked by two other researchers, who provided critical input on the results and analysis. The results in this article are presented as quotes from the original participant responses, providing evidence for the themes that arose. These, together with the critical review of two independent researchers, serve to establish both the credibility and dependability of the claims made in the article. The transferability of the claims is limited, considering the specific context in which this study took place.

\section{Ethical considerations}

This study received ethical clearance from the Institutional Ethics Committee (project regis- tration no. 09/8/16). Prior to participating in the study, invited panel members received an information sheet and were asked to state their consent to participate. Panellists were informed that their participation was voluntary and that non-participation would not affect them negatively. They could withdraw from the study at any stage and have their responses removed. All responses to the questions were anonymous so as to limit the possibility that comments made by panellists with more experience would be referred to.

\section{Results}

The results of the discussions are presented below according to the questions that informed the discussion. Panellists were asked what teaching strategies they would use to facilitate professional development and lifelong learning among their students, how best to develop the students' knowledge and skills, and how to support students' values and emotional responses to the clinical environment. The themes that emerged during the discussion included the following: teachers should model their own approach to continuous learning to students; they should use teaching strategies that are both varied and integrated; and they should include the roles of personal values and emotions in reflective learning activities.

\section{Demonstrate continuous personal learning}

Panel members were asked how they would facilitate a learning process among students that emphasised continuing professional development and lifelong learning, rather than focusing on only the technical aspects of competent practice. Participant responses are presented below and clearly demonstrate an emphasis on educators' openness to continuous professional development, as well as modelling their approach to students:

'I encourage [students] to read widely and challenge themselves and others by always asking "why"? I refer to the development of staff in the department, and my own professional and personal development. Informing students when I learn something new, when I learn from them, and from patients.

'I mention that I cannot teach them anything, but can only invite them to learn and that the only person who I can guarantee will learn from our [short] time together is myself.'

'Role-modelling is the way that makes the biggest impact. As often as possible during routine clinical activities I make a point of referring to my own need for learning and development when addressing the students. I often look things up in a book on the ward round to illustrate the need for ongoing learning and the fact that even at a senior clinical level the need for learning is ongoing.' 'We are not scared to admit that we do not know all the answers, even to clinical questions and use the same resources we provide for the students to look up the answers. Use humour in the learning and teaching room.'

\section{Integrate a variety of methods}

In addition to the development of an approach to lifelong learning, it was clear that having a set of basic knowledge and technical skills were important components of competent practice. These were identified by panellists, and included communication and technical skills, applying knowledge to practice, clinical reasoning, and critical thinking. The teaching strategies they suggested to determine how these aspects of professional practice could be developed are presented below. It is clear that participants recommend the integration of different teaching approaches during the same session:

'Integrating short role-play to teach communication skills (especially how to deal with the emotional content of patient interaction), immediately followed by bedside interview, and then reflection individually and in a safe small group. This followed by a compulsory formative assignment with a reflective component. Students comment that the role-play leads into the authentic clinical consultation very well.'

'Teaching strategies would include: clinical demonstrations on models and patients as well as return demonstrations, working with students through the following steps: observer, assistant, active performer with assistance, and finally active performer with minimal assistance but under supervision.

'Theory of the meaning of the practical technique of technical skill, and evidence for it. Demonstrate the technique and then let them practice while I correct and explain again what the techniques aim to do. In revision they demonstrate a practical technique and the class critique.'

\section{Incorporate values and emotions into reflective learning activities}

Panel members discussed the role that personal, affective components of learning can play in the students' development and professional practice. They were asked how they could support students' values and emotional responses 
to learning experiences in the clinical context. The panel highlighted intentional incorporation of personal values and emotions in students reflective learning tasks as important:

'The nature of the programme allows students to share personal values and experiences when discussing the cases. The students have to develop trust to be able to share in their groups, which improves as they become more comfortable with one another'.

'Students need opportunities for self-reflection that is structured, is written down and receives developmental feedback; they need to be given opportunities to develop their own sense of agency; if they are always passive in the health system as students then they will always be passive when professional.'

'Specifically asking students to express and discuss their personal values and emotional responses to patient encounters is a critical part of clinical training. Students need to express what they think and feel in the clinical setting so that they learn to deal with value issues and emotional responses to events in clinical practice'

\section{Discussion}

The overwhelming response from panel members was that there is a need to display an open attitude to their own personal continuous learning, thereby modelling to students what a process of lifelong learning entails. Panel members did not believe that clinical educators should have all the answers, and noted that the teachers' lack of knowledge can be used to drive and motivate student learning. This openness to display vulnerability and uncertainty has been identified as an attribute of positive role-models among clinical teachers. ${ }^{[12]}$ The panel also suggested that educators should model a process of inquiry to stay up to date in their respective fields, noting that role-modelling is an important process through which teachers demonstrate their own continued learning. Educators must therefore create safe spaces for students to explore the domain in collaboration with peers and the teacher, rather than simply informing students what to do and what they need to know. We need to help students to 'create paths to knowledge' when needed, ${ }^{[13]}$ and to focus on helping them to learn how to learn, a conception of teaching as a process that makes student learning possible. ${ }^{[9,14]}$ However, this approach to teaching and learning requires a cultural change among clinical educators. ${ }^{[4]}$

Panel members also suggested that a variety of teaching approaches should be used to develop knowledge and skills, and that these approaches should be integrated. For example, lectures could be used to cover key concepts prior to practical demonstrations, followed by observed practice by the students, and associated feedback. They suggested that teachers make use of tutorials and modelling, either in the classroom or in the clinical context. Role-play to explore different aspects of appropriate behaviour, followed by feedback from teachers and peers, was encouraged. Again, the concept of feedback was highlighted as an essential aspect of learning that could be used to guide future learning. ${ }^{[15]}$ There is evidence to suggest that, with appropriate guidance, peers are able to provide constructive feedback on performance that can be used to structure changes in future practice. ${ }^{[15]}$ Clinical educators should therefore consider the role of peer evaluation and feedback in their teaching sessions. Furthermore, reflection in small groups and by individuals immediately after receiving feedback was noted as having the potential to enhance student learning.

It was clear that panellists reported using combinations of teaching strategies, rather than suggesting only one approach. These integrated teaching and learning activities emphasised the connection and interaction between people, highlighting the idea that teaching and learning is a process that 'values human relationships. ${ }^{\text {'[16] }}$ This is in stark contrast to a knowledgetransmission form of teaching, where the teacher 'transmits' what should be known and the students passively 'receive' it, an approach that many clinical educators still subscribe to. ${ }^{[2]}$

Panel members reported that educators should encourage the sharing of personal values and experiences among students and clinicians, and evaluate the impact of those experiences on themselves. They should build reflective components into the curriculum, asking students how they feel about, and deal with, their emotional responses to the clinical context. Panel members also suggested that students be encouraged to provide evidence of engagement with their own emotional responses through reflective self-reporting, which should include a feedback component from peers and more experienced clinicians. The inclusion of a feedback component highlights the essential role that it plays in the shaping of students' values. ${ }^{[15,17]}$ However, it is important that this feedback is given in a safe space, as it can be linked to confusion, anxiety, embarrassment and lack of confidence. ${ }^{[14]}$ In some cases the feedback interaction is so negative that it has an emotional impact lasting several years, and can inhibit learning. ${ }^{[18]}$ Therefore, the sharing of personal experiences and the emotional response to those experiences, together with feedback from peers and teachers, require a caring and trusting relationship to be effective.

\section{Conclusion and recommendations}

To develop learning outcomes that go beyond knowledge and skills, clinical teachers should model an approach to lifelong learning for students, make use of an integrated variety of teaching methods, and intentionally incorporate the role of personal values and emotional response into students' learning activities. Teachers should also understand that these approaches are premised on the existence of a relationship between student and teacher, which encourages both of them to create space for the other to be vulnerable and admit to 'not knowing. Clinical educators in this study emphasised the developmental nature of the teaching and learning process, highlighting the importance of an authentic interaction between students and teachers. By engaging with shared learning experiences, we may be able to provide students with opportunities to develop the knowledge and mindsets necessary to participate in dynamic and complex health systems.

\section{References}

1. Frenk J, Chen L, Bhutta ZA, et al. Health professionals for a new century: Transforming education to strengthen healt systems in an interdependent world. Lancet 2010;376(9756):1923-1958. DOI:10.1016/S0140-6736(10)61854-5

2. Graffam B. Active learning in medical education: Strategies for beginning implementation. Med Teach 2007;29(1):38-42. DOI:10.1080/01421590601176398

. Cooke M, Irby DM, Sullivan W, Ludmerer KM. American medical education 100 years after the Flexner report. N Engl J Med 2006;355(13):1339-1344. DOI:10.1056/NEJMra055445

4. Fraser SW, Greenhalgh T. Coping with complexity: Educating for capability. BMJ 2001;323(7316):799-803. 4. Fraser SW, Greenhalgh T. Cop

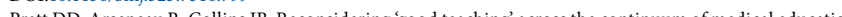
J Contin Educ Health Professions 2001;21(2):70-81. DOI:10.1002/chp.1340210203

6. Jarvis-Selinger S, Pratt DD, Regehr G. Competency is not enough: Integrating identify formation into the medical 6. Jarvis-Selinger S, Pratt DD, Regehr G. Competency is not enough: Integrating identify formation
education discourse. Acad Med 2012;87(9):1185-1190. DOI:10.1097/ACM.0b013e3182604968

7. Lombardi MM. Authentic learning for the 21st century: An overview. Educause Learning Initiative, May 2007. http://net.educause.edu/ir/library/pdf/ELI3009.pdf (accessed 25 July 2016).

8. Ovens P, Wells F, Wallis P, Hawkins C. Developing Inquiry for Learning: Reflecting Collaborative Ways to Learn How to Learn in Higher Education. London: Routledge, 2011.

9. Delbecq AL, van de Ven AH, Gustafson DH. Group Techniques for Program Planning: A Guide to Nominal Group and Delphi Processes. Glenview, Scotland: Foresman, 1975.

10. Cohen L, Manion L, Morrison K. Research Methods in Education. 6th ed. London: Routledge, 2007.

11. Pope C, Ziebland S, Mays N. Qualitative research in health care: Analysing qualitative data. BMJ 2000;320(7227):114-116. DOI:10.1136/bmj.320.7227.114

12. Jochemsen-van der Leeuw HG, van Dijk N, van Etten-Jamaludin FS, Wieringa-de Waard M. The attributes of the clinical trainer as a role model. Acad Med 2012;88(1):1-9. DOI:10.1097/ACM.0b013e318276d070

13. Anderson T. Theories for learning with emerging technologies. In: Veletsianos G, ed. Emerging Technologies in 3. Anderson T. Theories for learning with emerging technologies. In: Velets
Distance Education. Edmonton: Athabasca University Press, 2011:23-39.

14. Ramsden P. Learning to Teach in Higher Education. 2nd ed. London: Routledge, 2003.

15. Boud D, Molloy E. Feedback in Higher and Professional Education: Understanding It and Doing It Well. London Routledge, 2013.

6. Doll WE. A Post-Modern Perspective on Curriculum. New York: Teachers College Press, 1993.

17. Epstein RM. Assessment in medical education. N Engl J Med 2007;356(4):387-396. DOI:10.1056/NEJMra05478

18. Falchikov N, Boud D. Assessment and emotion: The impact of being assessed. In: Boud D, Falchikov N, eds Rethinking Assessment in Higher Education. Learning for the Longer Term. London: Routledge, 2007:144-156. 